\title{
Dorsoventral regulation of photosynthetic functions related to morphological and anatomical structures in field-grown sorghum
}

\author{
X. WANG ${ }^{* * *,+}$, Y. SHI ${ }^{*}$, Q. WANG ${ }^{* * *}$, and Y. $\mathrm{LI}^{\#}$ \\ Tobacco Research Institute of Chinese Academy of Agricultural Sciences, 266101 Qingdao, China* \\ Institute of Agricultural Resources and Regional Planning of Chinese Academy of Agricultural Sciences, \\ 100081 Beijing, China** \\ Guangdong Provincial Bioengineering Institute (Guangzhou Sugarcane Industry Research Institute), \\ 510316 Guangzhou, China*** \\ School of Resources and Environment, Henan University of Economics and Law, 450046 Zhengzhou, China
}

\begin{abstract}
The rapid dorsoventral regulation of photosynthesis is important because the light conditions around both surfaces of field-grown leaves vary considerably. The photosynthetic asymmetry has been intensively studied, but structure-related explanations for asymmetry were not exactly clarified. This study aimed to investigate the photosynthetic asymmetry in field-grown Sorghum bicolor L. and analyze the impacts of dorsoventral structures on photosynthesis. We found that the photosynthetic asymmetry changed with light conditions, and adaxial surfaces had higher primary photochemical activity owing to higher mesophyll density, while abaxial surfaces had higher $\mathrm{CO}_{2}$-diffusion capacity due to higher stomatal density, substomatal cavities, and contact areas between bundle sheath and mesophyll cells. Moreover, abaxial surfaces could mainly use self-transmitted light (residual light intercepted by adaxial surface) to drive photoreaction which could partly retain high photosynthetic rates in the field. This study can improve our understanding on the photosynthetic dorsoventral regulation.
\end{abstract}

Additional key words: chlorophyll a fluorescence; field; gas exchange; isobilateral leaf; leaf anatomy.

\section{Introduction}

The leaf morphology and anatomy play important roles in the regulation of photosynthesis, involving the $\mathrm{CO}_{2}$ diffusion and photosynthetic activity (Smith et al. 1997). According to the morphological and anatomical structures, higher plant leaves are divided into bifacial and isobilateral leaves. The variations in epidermal structure of two leaf surfaces (adaxial and abaxial surface), particularly, the stomatal density (SD) and stomata apparatus size on each surface, are common in bifacial species (Driscoll et al. 2006, Soares et al. 2008). In isobilateral leaves, the morphology of palisade tissue and spongy tissue is greatly different, and the photosynthesis changes with the variations of morphology and anatomy. When the leaf was illuminated from the adaxial surface, the photosynthetic capacity was $30-40 \%$ higher than that from abaxial one (Moss 1964). It was reported that the palisade tissue of the adaxial epidermis could collect and focus the incident light into the leaf interior, possibly to enhance photosynthetic rates (Long et al. 1989, Vogelmann et al. 1996). However, the loose spongy tissue of abaxial surface had large intercellular spaces, which were beneficial for $\mathrm{CO}_{2}$ diffusion (Terashima and Inoue 1984, Earles et al. 2017). The results from bifacial leaves of both $\mathrm{C}_{3}$ (Helianthus annuus) and $\mathrm{C}_{4}$ (Amaranthus retroflexus) plants demonstrated that the direct light was the driving force for photosynthesis, while the diffuse light played only minor roles (Brodersen and

$\overline{\text { Received }} 31$ July 2018, accepted 13 December 2018.

${ }^{+}$Corresponding author; phone: +86532 88703786, e-mail: aardvolf@163.com

Abbreviations: ABS - absorption energy flux; ABS/RC - the specific energy fluxes per reaction center for absorption; $\mathrm{AQE}$ - apparent quantum efficiency; ASC - the area of substomatal cavity; CABM - contact area between bundle sheath and mesophyll cells; $C_{\mathrm{i}}$ - intercellular $\mathrm{CO}_{2}$ concentration; $\mathrm{ET}$ - excitation energy for electron transport; $\mathrm{F}_{0}-$ minimal fluorescence yield of the darkadapted state; $F_{j}$ - the variable fluorescence intensity at $2 \mathrm{~ms} ; F_{k}$ - fluorescence intensity at $300 \mu \mathrm{s} ; \mathrm{F}_{\mathrm{m}}$ - maximal fluorescence yield of the dark-adapted state; $g_{\mathrm{s}}$ - stomatal conductance; LCP - compensated light intensity; LSP - saturated light intensity; MD - density of mesophyll cells; $\mathrm{M}_{\mathrm{o}}$ - the initial slope of the relative variable fluorescence kinetics; $\mathrm{PI}_{\mathrm{ABS}}$ - performance index; $P_{\mathrm{Nmax}}-$ the maximum photosynthetic rate; $P_{\mathrm{N}}$ - net photosynthetic rate; RC - reaction center of PSII; RC/CS - concentration of reaction centers per excited cross-section; SD - stomatal density; TR - trapping of excitation energy by a RC; $\mathrm{V}_{\mathrm{j}}$ - the variable fluorescence intensity at $2 \mathrm{~ms}$ ( $\mathrm{J}$ step); $\varphi_{D}$ - the quantum yield of dissipation; $\varphi_{E}$ - quantum yield of electron transport; $\varphi_{0}$ - efficiency with which a trapped exciton, having triggered the reduction of $\mathrm{Q}_{\mathrm{A}}$ to $\mathrm{Q}_{\mathrm{A}^{-}}$, can move an electron further than $\mathrm{Q}_{\mathrm{A}}^{-}$into the electron transport chain; $\varphi_{\mathrm{P}_{\mathrm{o}}}-$ maximum quantum yield of primary photochemistry.

Acknowledgments: We thank Prof. C.D. Jiang for the assistance with the experiments in the Institute of Botany, Chinese Academy of Sciences. 
Vogelmann 2010).

As we know, both sides of isobilateral leaves are not differentiated into palisade and spongy tissues but there are still obvious differences between two surfaces, i.e., the stomatal density (SD) (Soares et al. 2008, SoaresCordeiro et al. 2009, 2011). When an isobilateral leaf was illuminated from the abaxial surface, the photosynthetic capacities were higher than or equal to that from adaxial surface (Terashima and Inoue 1984, Long et al. 1989, DeLucia et al. 1991, Soares-Cordeiro et al. 2009). The variations of photosynthetic regulation between the adaxial and abaxial surfaces are determined by factors related to leaf anatomic structures. The light absorption, energy conversion and distribution and gas diffusion in a leaf were proved to regulate $\mathrm{CO}_{2}$ assimilation (Vogelmann et al. 1996, Soares et al. 2008, Sowiński et al. 2008, Falcioni et al. 2017). The total section area of the bundle sheath cells and the first layer of surrounding mesophyll related to $\mathrm{CO}_{2}$ diffusion within the leaf were also considered as the structural evidences of various $\mathrm{CO}_{2}$ assimilation between two leaf surfaces of $\mathrm{C}_{4}$ monocotyledonous species (Soares-Cordeiro et al. 2009). The leaf absorbance rates of adaxial side to incident light were greatly different from abaxial one, and the leaf structure could change the absorption of incident light (Gorton et al. 2010, Falcioni et al. 2017). Meanwhile, the adaptive changes in $\mathrm{CO}_{2}$ diffusion can be rapid and can be reversed by stomatal responses (Centritto et al. 2003, Flexas et al. 2007, Xiong et al. 2018). Most terrestrial plant species have hypostomatic or amphistomatic leaves with more stomata on abaxial surfaces. The location patterns of stomata on each leaf surface were also likely to influence significantly photosynthesis, which suggests that the distribution of stomata between the two surfaces provides an adaptive advantage under field conditions (Muir et al. 2014, Jordan et al. 2015, Richardson et al. 2017). The adaxial and abaxial leaf sides of $\mathrm{C}_{4}$ monocotyledonous species were considered to comprise essentially two separate compartments as there were physical restrictions to air space and each side independently regulated gas exchange (Long et al. 1989, SoaresCordeiro et al. 2009). The abaxial side with more stomata was more important for leaf integrated photosynthesis, regardless of adaxial or abaxial illumination (Soares et al. 2008, Soares-Cordeiro et al. 2009). One of the reasons for the dorsoventral differences in net photosynthetic rates $\left(P_{\mathrm{N}}\right)$ and light-use efficiency in isobilateral leaves was the higher SD on the abaxial surfaces (Soares et al. 2008, Jiang et al. 2011).

In most amphistomatous leaves, the stomata on both surfaces acclimated to various light environments with respect to intensity, wavelength composition (Wang et al. 2008), and the property (direct light or diffuse light) (Brodersen and Vogelmann 2010). In the field conditions, the adaxial surfaces are directly exposed in the direct light while the abaxial surfaces receive diffuse light and residual light intercepted by the adaxial surface (selftransmitted light). The light reaching abaxial side of the leaf (Eucalyptus globulus Labill ) was up to 10-20\% because of the intercept of the adaxial side (Earles et al. 2017), the self-transmitted light might account for considerable contribution to the whole leaf photosynthesis. The abaxial stomata might be more sensitive to the selftransmitted light than to the direct light in sun-grown leaves of Helianthus annuus (Wang et al. 2008), owing to more green light arriving at abaxial surfaces (Sun et al. 1998, Wang et al. 2008) and higher stomatal sensitivity to green light (Terashima et al. 2009). Generally speaking, $80-90 \%$ of visible light could be absorbed by leaves, and 10 and $5 \%$ of that is reflected and transmitted, respectively (Ehleringer and Björkman 1978, Bird and Riordan 1986). To our best knowledge, it has not been yet investigated how the abaxial surfaces balance the simultaneous diffuse and self-transmitted light under the field conditions.

Sorghum, a typical $\mathrm{C}_{4}$ plant with isobilateral leaves, is one of the most important energy crops with a high yield of biomass around the world. Here, we investigated the morphological and anatomical variations between two surfaces and the response of photosynthetic traits to incident and self-transmitted light in the field-grown sorghum leaves. The aim of this study was to examine the structural reason for dorsoventral symmetry of photosynthesis in fieldgrown sorghum leaves, and to analyze how the leaf regulated photosynthesis in response to diverse light environment under the field conditions.

\section{Materials and methods}

Plant materials and growth conditions: Experiments were carried out at an experiment field in Beijing (115.7$117.4^{\circ} \mathrm{E}, 39.4-41.6^{\circ} \mathrm{N}$ ) from June to August 2016. Beijing is located in a northern temperate zone with a semi-humid, continental, and monsoon climate. Sorghum seeds were imbibed on wet paper for $1 \mathrm{~d}$, and germinated seeds were sown in containers $(30 \times 20 \times 10 \mathrm{~cm})$ filled with vermiculite. Plants were watered every $2 \mathrm{~d}$. One week later, the fourleaf seedlings were transplanted into plastic pots $(15 \mathrm{~cm}$ in diameter, $20 \mathrm{~cm}$ in height) containing Hoagland nutrient solution and grown in a site with simple rain shelters in the field. The nutrient solution was renewed every $3 \mathrm{~d}$. The seedlings were used for measurements after $20 \mathrm{~d}$.

Measurement of leaf optical properties: The leaf reflectance and transmittance on each surface of sorghum leaves were measured with a bifurcated fiber optic cable and a leaf clip (PP Systems, USA). The attached leaves used for gas-exchange measurements were measured across the spectrum of $400-800 \mathrm{~nm}$ at $1-\mathrm{nm}$ intervals. To calculate reflectance $(\%)$, the leaf spectral radiance was divided by the radiance of a $99 \%$ reflective white reference standard (Spectralon, Labsphere, North Dutton, NH, USA) (for more details see Gamon and Surfus 1999). The leaf transmittance (\%) was measured with two straight-fiber optics and a custom-made device. One straight-fiber optic was used to irradiate from the illuminated leaf side, and the other was used as a detector from the non-illuminated leaf side. The absorptance ( $\%)$ was the rest part of the incident light: absorbance $=1$ - reflectance - transmittance. Fully expanded leaves from twenty four plants were selected for measurements. 
The gas-exchange measurements were performed using an infrared gas analyzer ( $\mathrm{Li}-6400, \mathrm{Li}$-Cor, Lincoln, NE) equipped with a red-blue LED light source. The light source could provide direct light with the intensity from 0 to $2,000 \mu \mathrm{mol}$ (photon) $\mathrm{m}^{-2} \mathrm{~s}^{-1}$ with $90 \%$ red and $10 \%$ blue light. In order to measure the specific gas exchange of each leaf surface, a well-designed method was used: a transparent film (TF) with no obvious effect on light intensity and absorbance rates (400-800 $\mathrm{nm}$ ) was used to block the gas flux between leaf surface and chamber of the analyzer (Li-6400). In this way, the gas-exchange rates of the opposite surface were measured. The leaf photosynthesis, specific photosynthesis of each leaf in incident and selftransmitted light were measured in three cases (Fig. 1): (1) Leaf photosynthesis with adaxial illumination or abaxial illumination: incident light illuminated each surface respectively. (2) Specific photosynthesis of adaxial or abaxial surface in incident light: incident light illuminated the target surface with blocking the no-target surface with $\mathrm{TF}$, i.e., adaxial photosynthesis was the photosynthesis with adaxial surface illuminated and abaxial surface blocked. (3) Specific photosynthesis of adaxial or abaxial surface in self-transmitted light: incident light illuminated no-target surface by blocking the illuminated surface with TF.
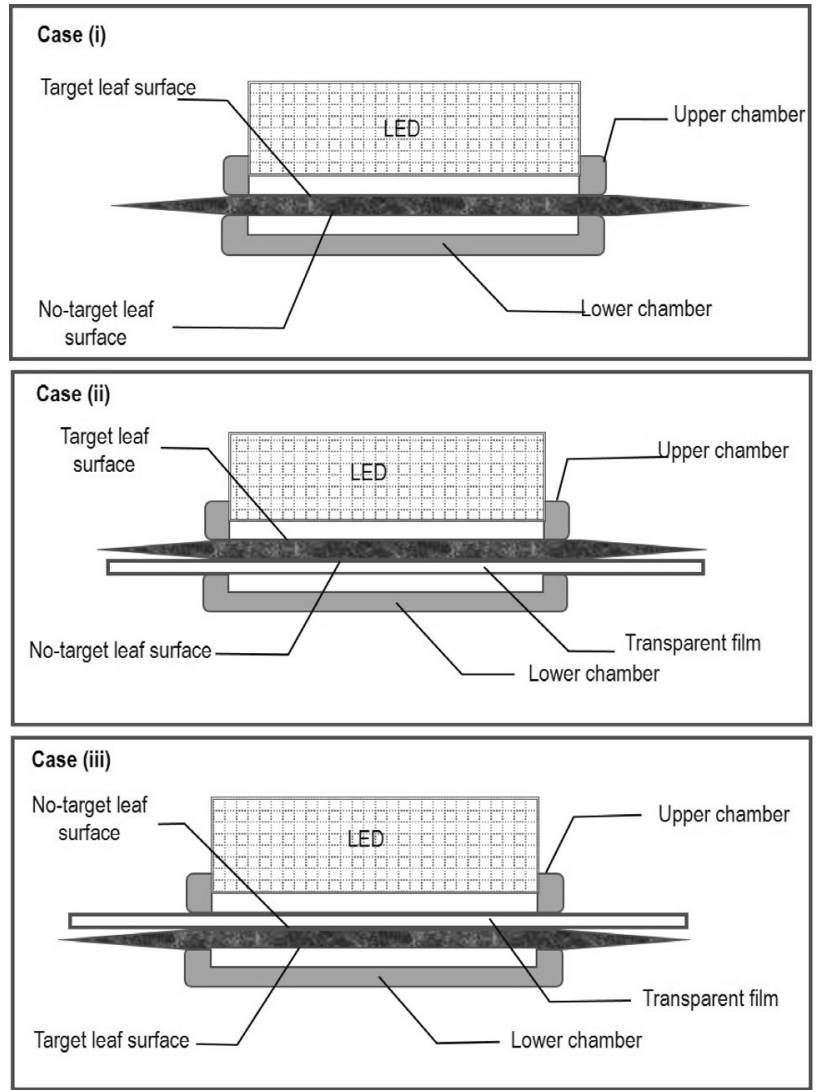

Fig. 1. Design of measuring the integrate and specific gas exchanges of a leaf in incident light and self-transmitted light. Case (i), the integrated leaf photosynthesis; Case (ii), the specific photosynthesis of adaxial or abaxial surface in incident light; Case (iii), the specific photosynthesis of adaxial or abaxial surface in self-transmitted light.
The newly developed fully expanded leaves from 24 plants were selected for measurement in this experiment. The plants were measured in batches either for the integrate or specific measurements. Measurements were conducted from 9:00 to $12: 00 \mathrm{~h}$ in a chamber with relative humidity of $45-50 \%$ and ambient $\mathrm{CO}_{2}$ concentration of $380 \mu \mathrm{mol}$ $\mathrm{mol}^{-1}$. Leaf surface temperatures were measured by a pair of thermocouples attached to the adaxial and abaxial surfaces. In all experiments, both the adaxial and abaxial surface temperatures were kept at $30^{\circ} \mathrm{C}$, by detecting the temperature of two half-chambers. Boundary layer conductances were measured with wet filter paper. In the experiments, the boundary layer conductances at the flow rate of $500 \mu \mathrm{mol} \mathrm{s}^{-1}$ were $1.74 \mathrm{~mol} \mathrm{~m}^{-2} \mathrm{~s}^{-1}$ and $1.82 \mathrm{~mol} \mathrm{~m}^{-2} \mathrm{~s}^{-1}$ for the adaxial and abaxial half-chambers, respectively. The light-response curves for leaf net photosynthetic rates $\left(P_{\mathrm{N}}\right)$ and stomatal conductance $\left(g_{\mathrm{s}}\right)$ of adaxial illumination and abaxial illumination were investigated in sorghum leaves with the incident light intensity gradient: 2,000; 1,$800 ; 1,600 ; 1,400 ; 1,200 ; 1,000 ; 800,600,400,300,250$, $200,150,100,50,20$, and $0 \mu \mathrm{mol}$ (photon) $\mathrm{m}^{-2} \mathrm{~s}^{-1}$. The intercellular $\mathrm{CO}_{2}$ concentration $\left(C_{\mathrm{i}}\right)$ was corresponding to the values of $P_{\mathrm{N}}$ and $g_{\mathrm{s}}$ under adaxial and abaxial illumination, respectively. The light-response curves for specific $P_{\mathrm{N}}$ and $g_{\mathrm{s}}$ under incident light and self-transmitted light were investigated with the same incident light intensity gradient as the above measurements. Our preliminary study of leaf optical properties showed that the reflectance rates of either surface were $10 \%$, and absorbance rates of two surfaces were $85 \%$ under the light of LED (90\% red and $10 \%$ blue light). We assumed that the absorbance rate of two surfaces was the same, so the residual light reflected and intercepted by illuminating side was $47.5 \%$ of the incident light. Thus, the photosynthetic light-response curves under incident and self-transmitted light were obtained respectively by using the full and $47.5 \%$ of incident light intensity as the actual PPFD ( PPFD $\left._{\text {act }}\right)$. The maximum photosynthetic rate $\left(P_{\mathrm{Nmax}}\right)$, compensated light intensity (LCP), saturated light intensity (LSP), and apparent quantum efficiency (AQE) of specific surface were calculated from the light-response curves for specific $P_{\mathrm{N}}$, using nonrectangular hyperbola fitting.

The Chl $\boldsymbol{a}$ fluorescence was measured with a $P E A$ fluorimeter (Plant Efficiency Analyzer, Hansatech Instruments Ltd., King's Lynn, UK) on completely expanded leaves. All measurements were done on fully dark-adapted (12 h) leaves. The leaves were then exposed to a pulse of saturated light at an intensity of 3,500 $\mu \mathrm{mol}$ (photon) $\mathrm{m}^{-2} \mathrm{~s}^{-1}$ and a wavelength of $650 \mathrm{~nm}$ for $5 \mathrm{~s}$. The fluorescence transients were recorded from $10 \mu$ s to $1 \mathrm{~s}$ (Strasser et al. 2004). The following original data was retained: the maximal measured fluorescenceintensity $\left(\mathrm{F}_{\mathrm{m}}\right)$; thefluorescenceintensity at $50 \mu$ s considered as the intensity $\mathrm{F}_{0}$; the fluorescence intensity at $300 \mu \mathrm{s}\left(\mathrm{F}_{\mathrm{k}}\right)$ required for the calculation of the initial slope $\left(\mathrm{M}_{0}\right)$ of the relative variable fluorescence $(\mathrm{V})$ kinetics and the variable fluorescence intensity at $2 \mathrm{~ms}$ ( $\mathrm{J}$ step, $\mathrm{F}_{\mathrm{j}}$ ), denoted as $\mathrm{V}_{\mathrm{j}}$ :

$\mathrm{M}_{0}=4 \times\left(\mathrm{F}_{\mathrm{k}}-\mathrm{F}_{0}\right) /\left(\mathrm{F}_{\mathrm{m}}-\mathrm{F}_{0}\right)$

$\mathrm{V}_{\mathrm{j}}=\left(\mathrm{F}_{\mathrm{j}}-\mathrm{F}_{0}\right) /\left(\mathrm{F}_{\mathrm{m}}-\mathrm{F}_{0}\right)$ 
The initial stage of photosynthetic activity of a reaction center (RC) complex was regulated by three functional steps: absorption events of light energy (ABS), trapping of excitation energy (TR), and conversion of excitation energy to electron transport (ET). A performance index $\left(\mathrm{PI}_{\mathrm{ABS}}\right)$ was introduced to comprehensively express these independent steps (Tsimilli-Michael et al. 2000, Van Heerden et al. 2004):

$$
\mathrm{PI}_{\mathrm{ABS}}=\mathrm{RC} / \mathrm{ABS} \times \frac{\varphi_{\mathrm{Po}}}{1-\varphi_{\mathrm{Po}}} \times \frac{\varphi_{\mathrm{o}}}{1-\varphi_{\mathrm{o}}}
$$

where RC/ABS was the amount of active PSII reaction centers per total absorption:

$$
\mathrm{RC} / \mathrm{ABS}=\varphi_{\mathrm{Po}} \times \mathrm{V}_{\mathrm{j}} / \mathrm{M}_{0}
$$

We obtained the quantification of PSII behavior referring to time zero (start of fluorescence induction): the maximum quantum yield of primary photochemistry:

$\varphi_{\text {Po }}=\mathrm{TR}_{0} / \mathrm{ABS}=1-\mathrm{F}_{0} / \mathrm{F}_{\mathrm{m}}$

the efficiency with which a trapped exciton, having triggered the reduction of $\mathrm{Q}_{\mathrm{A}}$ to $\mathrm{Q}_{\mathrm{A}^{-}}$, can move an electron further than $\mathrm{Q}_{\mathrm{A}}^{-}$into the electron transport chain:

$\varphi_{\mathrm{o}}=\mathrm{ET}_{0} / \mathrm{TR}_{0}=1-\mathrm{V}_{\mathrm{j}}$

the quantum yield of electron transport:

$\varphi_{\mathrm{E}}=\mathrm{ET}_{0} / \mathrm{ABS}=\varphi_{\mathrm{Po}} \times \varphi_{\mathrm{o}}$

the quantum yield of dissipation:

$\varphi_{\mathrm{D}}=\mathrm{DI}_{0} / \mathrm{ABS}=\mathrm{F}_{0} / \mathrm{F}_{\mathrm{m}}$

the specific energy fluxes per RC for absorption:

$\mathrm{ABS} / \mathrm{RC}=\mathrm{M}_{0} \times\left(1 / \mathrm{V}_{\mathrm{j}}\right) \times\left(1 / \varphi_{\mathrm{Po}}\right)$

the concentration of reaction centers per excited cross section of a given leaf:

$\mathrm{RC} / \mathrm{CS}=\varphi_{\mathrm{Po}_{\mathrm{o}}} \times\left(\mathrm{V}_{\mathrm{j}} / \mathrm{M}_{0}\right) \times \mathrm{F}_{0}$

Stomatal density and size on each leaf surface: The SD was determined according to the method of 'leaf imprints', which was described by Coupe et al. (2006) and Jiang et al. (2011). Once the leaves became fully expanded, a widely used nail polish (the main constituents were nitrocellulose and ethyl acetate) was applied to imprint to obtain a replica of the leaf surfaces. The replicas were observed under a light microscope (Olympus BH-2; Olympus Optical Co. Ltd., Tokyo, Japan) and a digital camera was used to photograph the replicas. The samples were taken from the same areas of the leaves that were used for the gasexchange measurements. The number of the stomata for each microphotograph was counted to calculate the SD. We measured the long axis of each stoma to reflect the size of stoma, because the short axis of stomata was difficult to measure when the stomata were almost closed. Six microphotographs were selected from the ten marked leaves from ten individual plants for each treatment.
Fixation, embedding, and sectioning of leaves for optical microscopy: The leaf sections $(2 \times 2 \mathrm{~mm})$ were immersed in the fixative, which consisted of $1 \%(\mathrm{v} / \mathrm{v})$ paraformaldehyde and $3 \%(\mathrm{v} / \mathrm{v})$ glutaraldehyde in 0.1 mol L ${ }^{-1}$ sodium phosphate buffer. The sections were then washed three times (15 min each) in the same buffer, and then post-fixated in toluidine blue $(1 \%, \mathrm{v} / \mathrm{v})$ in $0.1 \mathrm{~mol} \mathrm{~L}^{-1}$ sodium phosphate buffer and washed three times in the same buffer for $15 \mathrm{~min}$. The samples were dehydrated at ambient temperature using a graded ethanol series [35, $50,70$, and $96 \%(\mathrm{v} / \mathrm{v})]$ and twice at $100 \%$ ethanol with 30-min exposure at each step. After a graded ethanol series, the samples were embedded in Spurr's resin. The samples were finally transferred to flat embedding moulds filled with resin and polymerized at $65^{\circ} \mathrm{C}$ for $12 \mathrm{~h}$. The transverse semi-thin leaf sections $(1 \mu \mathrm{m})$ were observed using a light microscopy (Nikon-E800, Scientific Imaging Inc., USA).

The density of mesophyll cells (MD), the area of substomatal cavity (ASC), and contact area between bundle sheath and mesophyll cells (CABM) in transverse semithin leaf sections were based on Soares-Cordeiro et al. (2009) and $\mathrm{Wu}$ et al. (2014). CABM was calculated according to the following specific steps: (1) assuming that mesophyll cells were spheroids according to Thain (1983), the total cell surface area per unit volume of tissue was equal to the total length of cell profile perimeter in unit area of tissue section; (2) the length and the width of cells could be easily measured, the curvature correction factors (F) could be calculated by length/width ratio; (3) contact area of chloroplast facing to outer mesophyll cells was considered as: $\mathrm{CABM}=\mathrm{L}_{\mathrm{c}} / \mathrm{W} \times \mathrm{F}$, where $\mathrm{L}_{\mathrm{c}}$ was the length of chloroplasts facing the mesophyll cells and $\mathrm{W}$ was the width of the leaf cross-section. The values of $F$ in mesophyll cells of sorghum leaves were 1.45 in the calculation, and the values of $\mathrm{W}$ were calculated in the pictures of transverse semi-thin leaf sections with Image J-Fiji software.

Measurement of light conditions around two surfaces under the field conditions: Daily courses of direct (A) and diffuse (B) light were investigated using the light flux meter (QMSS, Apogee Instruments Inc., USA) in clear sky conditions. Light hitting vertically the upper and lower surface was regarded as the direct light and diffuse light, respectively. The self-transmitted light was calculated by direct light using the $47.5 \%$ transmittance; the transmittance was obtained from the leaf optical properties. Leaves toward east, south, west, and north were selected for investigation, respectively. With this method, 24 plants were selected to measure the PPFD.

Statistical analysis: Data were subjected to separate statistical analyses using Statistical Package for Social Sciences (SPSS, Version 18.0 for Windows). A pairedsamples $t$-test was used to analyze the gas-exchange data and morphological parameters, such as SD, ASC, and CABM. This test was also used to compare adaxial and abaxial fluorescence parameters. The independentsamples $t$-test was applied to compare $P_{\mathrm{Nmax}}$, LCP, LSP, 
and AQE of two surfaces in incident and self-transmitted light. The graphics software SigmaPlot (Version 10.0) was used to create artwork.

\section{Results}

Daily courses of direct and diffuse light: The diurnal changes in PPFD from different orientations (east, south, west, and north) above the canopy under clear sky conditions were presented in Fig. 2. The PPFD of the direct light was low in the morning $(8: 00 \mathrm{~h})$, increased gradually to a maximum value at $12: 00 \mathrm{~h}$ at all the orientations, and then decreased. Under the clear sky conditions, the daily maximum PPFD of direct light was found at the east orientation $\left[1,525 \mu \operatorname{mol}\left(\right.\right.$ photon) $\mathrm{m}^{-2}$ $\left.\mathrm{s}^{-1}\right]$. The PPFD of diffuse light varied greatly during the day, and the maximum PPFD [250 $\mu$ mol(photon) $\mathrm{m}^{-2} \mathrm{~s}^{-1}$ ] was reached at 10:00-12:00 h. The PPFD of diffuse light (Fig. 2B) was much lower than that of direct (Fig. 2A) and self-transmitted (Fig. 2C) light at all orientations during most of day time (10:00-16:00 h).

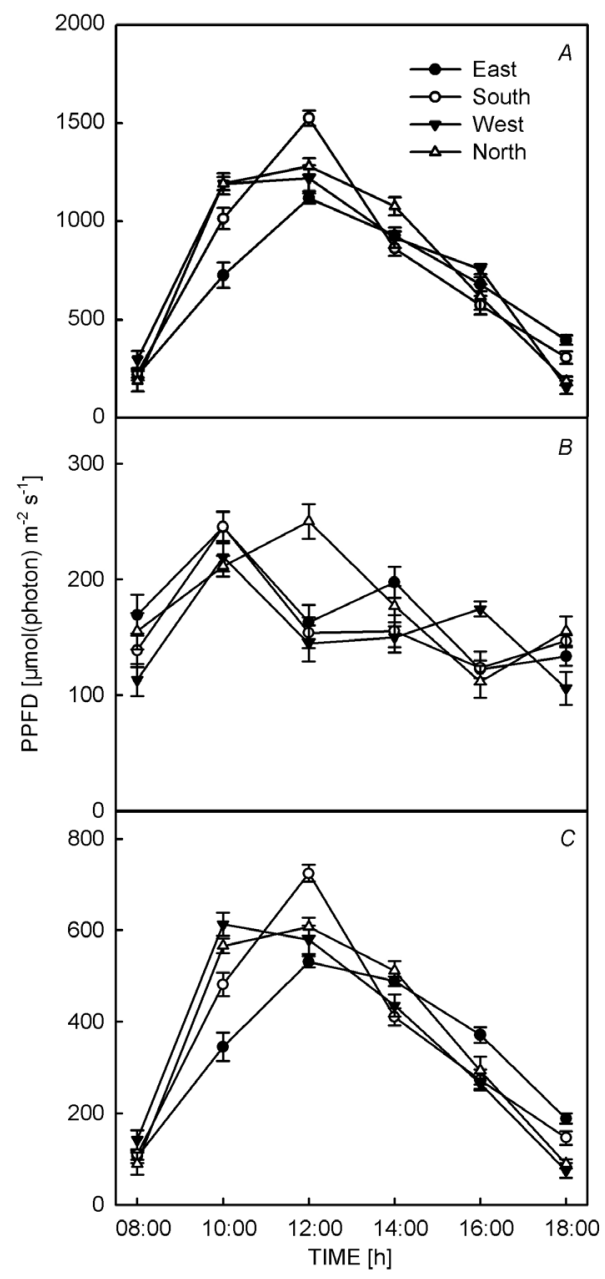

Fig. 2. Daily variations of PPFD from east (closed circles), south (open circles), west (closed triangles), and north (open triangles) orientation in direct $(A)$, diffuse $(B)$, and calculated selftransmitted $(C)$ light. Data are means $\pm \mathrm{SE}, n=24$.
Leaf optical properties of each surface: The leaf absorptance and reflectance rates of sorghum leaf with illuminating both the adaxial and abaxial surfaces were shown in Fig. 3. Two absorption peaks were observed at 500 and $660 \mathrm{~nm}$ regardless of the illuminating orientations. The maximum absorptance rate was $85 \%$ at $660 \mathrm{~nm}$ and the minimum absorptance rate was $25 \%$ at $800 \mathrm{~nm}$ in both illuminating cases. There was no substantial difference of leaf absorptance and reflectance rates between two illuminating cases over the bands from 400 to $800 \mathrm{~nm}$ in sorghum leaves.

Variations of stomatal density and leaf structure between two surfaces: Both sides of leaves had stomata, and the SD in abaxial surfaces were 1.5 times greater than that of the adaxial surfaces (Table 1), while the adaxial stomata lengths were approximately the same as the abaxial values (Table 1). The transverse sections showed that the vascular bundles were rounded by parenchyma cells. Further analysis showed that the MD was significantly higher at the adaxial side than that of abaxial side (Table 1). While the abaxial side had much larger ASC than that of adaxial one, the CABM of abaxial surfaces was also significantly higher than that of adaxial surfaces (Table 1).

Variations of gas exchange between two surfaces in incident and self-transmitted light: As PPFD increased, $P_{\mathrm{N}}$ and $g_{\mathrm{s}}$ increased proportionally regardless of the adaxial or abaxial illumination, both the $P_{\mathrm{N}}$ with adaxial and abaxial illumination could maintain more than $35 \mu \mathrm{mol}$ $\mathrm{m}^{-2} \mathrm{~s}^{-1}$ under saturated light (Fig. 4). The $P_{\mathrm{N}}$ with adaxial illumination was about $10 \%$ higher than that with abaxial illumination for middle and high PPFD values $[>500$ $\mu$ mol(photon) $\mathrm{m}^{-2} \mathrm{~s}^{-1}$. The variations of $P_{\mathrm{N}}$ between adaxial and abaxial illumination were not obvious when the light intensity was more than $1,800 \mu$ mol(photon) $\mathrm{m}^{-2} \mathrm{~s}^{-1}$. There was no clear difference in $g_{\mathrm{s}}$ and $C_{\mathrm{i}}$ between adaxial and abaxial illumination in all the PPFD levels (Fig. 4B,C).

The specific $P_{\mathrm{N}}$ and $g_{\mathrm{s}}$ were obviously different between the two surfaces, especially at high PPFD (Fig. 5A,B). In the incident light, the adaxial $P_{\mathrm{N}}$ was a little higher than that of the abaxial one before the PPFD reached the maximum at $600 \mu \mathrm{mol}$ (photon) $\mathrm{m}^{-2} \mathrm{~s}^{-1}$, while the abaxial specific $P_{\mathrm{N}}$ was higher than that of the adaxial one when the PPFD exceeded 1,000 $\mu \mathrm{mol}$ (photon) $\mathrm{m}^{-2} \mathrm{~s}^{-1}$ (Fig. 5A). The specific $P_{\text {Nmax }}$ and LSP of the abaxial surface were significantly higher than that of abaxial surface (Table 2). The specific AQE was significantly higher at the adaxial surface, while the specific LCP was higher at the abaxial surface. The difference of specific $g_{s}$ between two surfaces changed with the $P_{\mathrm{N}}$ both in incident light and selftransmitted light. When the unilateral surfaces were exposed to self-transmitted light, there was a great variation of specific $P_{\mathrm{N}}$ and $g_{\mathrm{s}}$ between two surfaces. The abaxial $P_{\mathrm{N} \max }$ under self-transmitted light was 3-fold higher than that of the adaxial one. But the abaxial LCP was significantly higher and $\mathrm{AQE}$ was significantly lower than that of the adaxial ones. The abaxial $P_{\mathrm{N}}$ and $g_{\mathrm{s}}$ in selftransmitted light were considerably higher than that of 


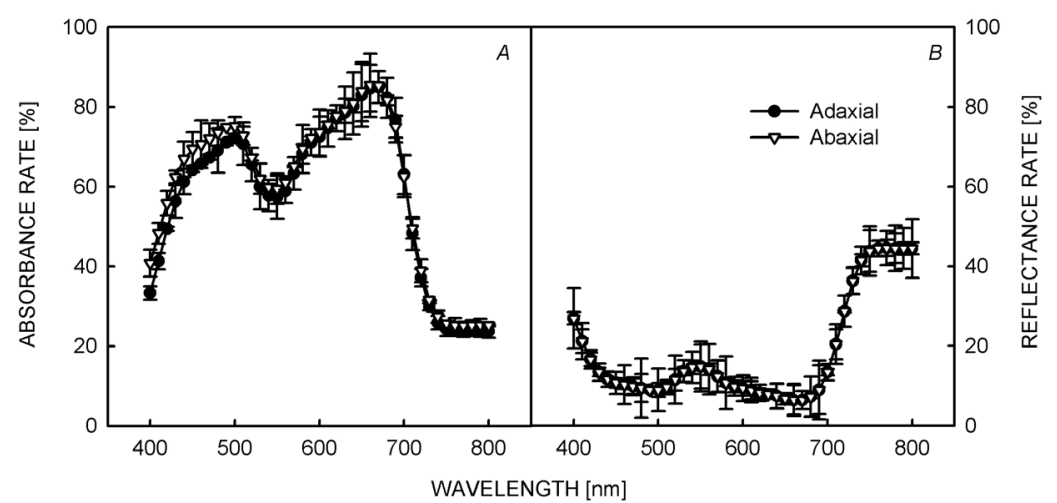

Fig. 3. Variations of leaf absorbance $(A)$ and reflectance $(B)$ rates when illuminating the adaxial (closed circles) and abaxial (open triangles) surface, respectively. Data are means \pm SE, $n=24$.

Table 1. Variations of stomatal density (SD), the long axis of stomatal aperture, the density of mesophyll cells (MD), the area of substomatal cavity (ASC), and the contact area between bundle sheath and mesophyll cells (CABM) between the adaxial and abaxial side in sorghum. The parameters were calculated from $n$ samples.

\begin{tabular}{llllll}
\hline & $\mathrm{SD}\left[\mathrm{mm}^{-2}\right]$ & $\begin{array}{l}\text { Long axis of stomatal } \\
\text { aperture }[\mu \mathrm{m}]\end{array}$ & $\mathrm{MD} \times 10^{2}\left[\mathrm{~mm}^{-2}\right]$ & $\mathrm{ASC}\left[\mu \mathrm{m}^{2}\right]$ & $\mathrm{CABM}\left[\mathrm{m}^{2} \mathrm{~m}^{-2}\right]$ \\
\hline Adaxial & $78.62 \pm 2.10$ & $31.23 \pm 2.31$ & $78.75 \pm 6.82$ & $76.70 \pm 7.05$ & $2.12 \pm 0.20$ \\
Abaxial & $126.50 \pm 3.30$ & $30.30 \pm 2.18$ & $51.74 \pm 9.38$ & $262.28 \pm 23.15$ & $2.53 \pm 0.30$ \\
Adaxial/abaxial & 0.62 & 1.02 & 1.52 & 0.29 & 0.84 \\
n & 108 & 120 & 20 & 20 & 20 \\
$P$-value & $<0.01$ & 0.056 & $<0.001$ & $<0.01$ & $<0.01$ \\
\hline
\end{tabular}

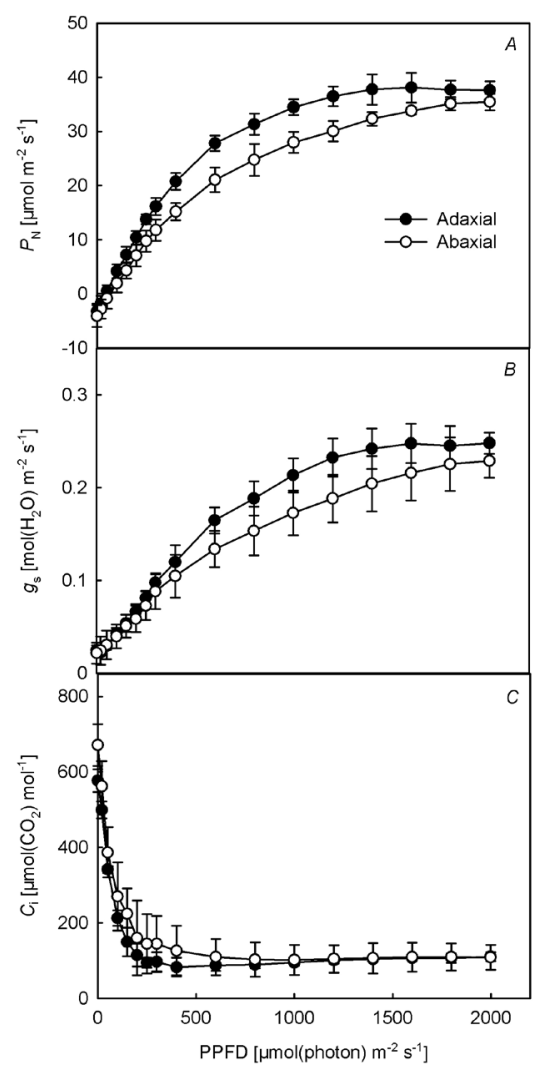

Fig. 4. Light-response curves for integrated net photosynthetic rate $\left(P_{\mathrm{N}}\right)(A)$, stomatal conductance $\left(g_{\mathrm{s}}\right)(B)$, and intercellular carbon dioxide concentration $\left(C_{\mathrm{i}}\right)(C)$ of sorghum leaves when illuminating the adaxial surface (closed circles) and abaxial surface (open circles). Data are means $\pm \mathrm{SE}, n=24$. the adaxial ones at most levels of PPFD (Fig. $5 B, D$ ). The LCP, LSP, and AQE of adaxial side were non-significant between incident light and self-transmitted light (Table 2).

Variations of adaxial and abaxial surface in Chl $\boldsymbol{a}$ fluorescence: There was no significant difference between the two surfaces in $\varphi_{\text {Po }}$ (Fig. 6C), but the $\mathrm{F}_{0}$ after dark adaptation appeared slightly higher for the abaxial surfaces than that of adaxial ones (Fig. $6 A$ ). The $\mathrm{PI}_{\mathrm{ABS}}$ was significantly lower at the abaxial surface (Fig. $6 E$ ), indicating the lower chemical activity of PSII of the abaxial surface. The RC/CS was significantly lower at the abaxial surface than that of adaxial surface, while there was no significant difference in $\varphi_{\mathrm{E}}$ and the ABS/RC between the two surfaces (Fig. 6B,D,F).

\section{Discussion}

Variations of photosynthesis between two surfaces of field-grown sorghum: Our study showed that the specific $P_{\mathrm{N}}$ of the abaxial surface of sorghum leaves was mostly higher than that of the adaxial one, especially under high incident light (Fig. 5A). However, the integrated $P_{\mathrm{N}}$ of adaxial illumination was significantly higher than that of the abaxial surface (Fig. 4A). Our results of transverse sections showed the sorghum leaf was divided into two separate compartments by compactly arranged mesophyll cells, as in other $\mathrm{C}_{4}$ monocotyledonous species in previous reports (Long et al. 1989, Morison and Lawson 2007, Smith 2008, Soares-Cordeiro et al. 2009). Thus, there was no conductance to $\mathrm{CO}_{2}$ diffusion between the upper and lower substomatal cavities in the experimental materials; each surface independently regulated gas exchange. The leaf $g_{\mathrm{s}}$ and $C_{\mathrm{i}}$ showed no significant difference between the 


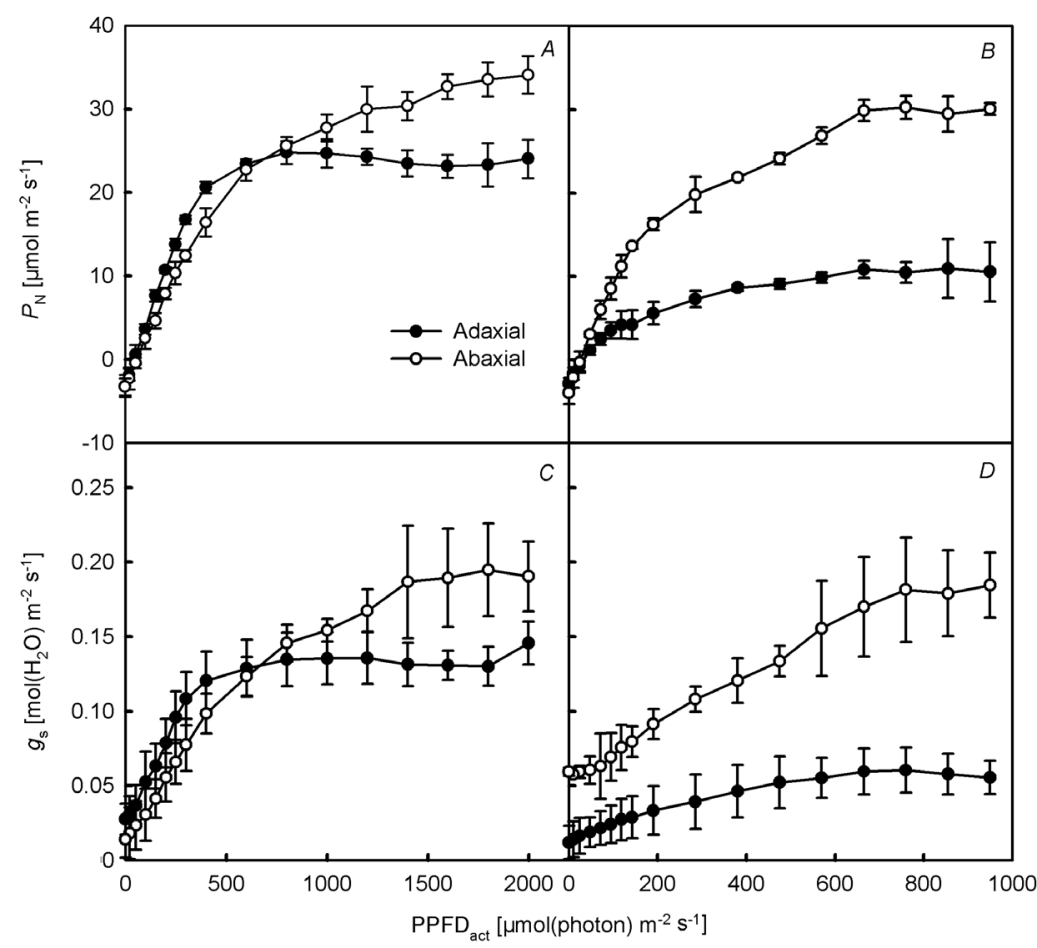

Fig. 5. Light-response curves for the specific photosynthetic rates $\left(P_{\mathrm{N}}\right)(A, B)$, stomatal conductance $\left(g_{\mathrm{s}}\right)(C, D)$ of adaxial surface (closed circles) and abaxial surface (open circles) in sorghum leaves in incident light $(A, C)$ and self-transmitted light $(B, D)$. Data are means $\pm \mathrm{SE}, n=24$.

Table 2. Variation of the maximum photosynthetic rate $\left(P_{\mathrm{Nmax}}\right)$, the compensated light intensity (LCP), the saturated light intensity (LSP), and the apparent quantum efficiency (AQE) of specific surface when the sorghum leaves were illuminated by incident and selftransmitted light. Means \pm SE, $n=24$. Different letters showed the significant difference between the two surfaces and two illuminating lights $(P=0.01)$.

\begin{tabular}{llllll}
\hline & & $\begin{array}{l}P_{\mathrm{Nmax}} \\
{\left[\mu \operatorname{mol}\left(\mathrm{CO}_{2}\right) \mathrm{m}^{-2} \mathrm{~s}^{-1}\right]}\end{array}$ & $\begin{array}{l}\text { LCP } \\
{\left[\mu \mathrm{mol}(\text { photon}) \mathrm{m}^{-2} \mathrm{~s}^{-1}\right]}\end{array}$ & $\begin{array}{l}\text { LSP } \\
{\left[\mu \mathrm{mol}(\text { photon}) \mathrm{m}^{-2} \mathrm{~s}^{-1}\right]}\end{array}$ & AQE \\
\hline Incident light & Adaxial & $24.30 \pm 2.23^{\mathrm{c}}$ & $44.57 \pm 2.43^{\mathrm{b}}$ & $785.33 \pm 22.35^{\mathrm{c}}$ & $0.067 \pm 0.006^{\mathrm{a}}$ \\
& Abaxial & $36.54 \pm 1.25^{\mathrm{a}}$ & $59.28 \pm 3.19^{\mathrm{a}}$ & $1,914.19 \pm 31.12^{\mathrm{a}}$ & $0.053 \pm 0.002^{\mathrm{b}}$ \\
\multirow{3}{*}{ Self-transmitted light } & Adaxial & $11.23 \pm 1.36^{\mathrm{d}}$ & $47.74 \pm 3.34^{\mathrm{b}}$ & $743.62 \pm 37.14^{\mathrm{c}}$ & $0.068 \pm 0.002^{\mathrm{a}}$ \\
& Abaxial & $30.32 \pm 2.02^{\mathrm{b}}$ & $62.24 \pm 2.58^{\mathrm{a}}$ & $1,548.56 \pm 26.64^{\mathrm{b}}$ & $0.041 \pm 0.002^{\mathrm{b}}$ \\
\hline
\end{tabular}

adaxial and abaxial illumination (Fig. $4 B, C$ ), indicating that the total of $\mathrm{CO}_{2}$ diffusion (adaxial + abaxial) of the leaf was nearly the same regardless of illuminating orientations. Nevertheless, when a leaf was illuminated on each surface, one surface would be exposed to incident light, while the other would be exposed to self-transmitted light. The marked differences of $P_{\mathrm{N}}$ between adaxial and abaxial illumination (Fig. 4A) might be caused by the different proportions of specific $g_{\mathrm{s}}$ in the total $\mathrm{CO}_{2}$ diffusion. When the specific $P_{\mathrm{N}}$ was measured by using a TF, dorsoventral variations in high PPFD act $\left[>1,000 \mu \mathrm{mol}\left(\right.\right.$ photon) $\left.\mathrm{m}^{-2} \mathrm{~s}^{-1}\right]$ were mostly marked (Fig. $5 A, B$ ), and the specific $g_{\mathrm{s}}$ of each surface was also greatly different from each other (Fig. 5C,D). The abaxial specific $P_{\mathrm{Nmax}}$ was 1.5 times higher than that of the adaxial one, and when the PPFD reached $600 \mu \mathrm{mol} \mathrm{m} \mathrm{s}^{-1}$, the adaxial specific $P_{\mathrm{N}}$ was saturated at $785.3 \mu \mathrm{mol}$ (photon) $\mathrm{m}^{-2} \mathrm{~s}^{-1}$, while the specific abaxial $P_{\mathrm{N}}$ could continue to increase until the PPFD reached 1,914 $\mu \mathrm{mol}$ (photon) $\mathrm{m}^{-2} \mathrm{~s}^{-1}$. The higher abaxial specific $P_{\mathrm{N}}$ of sorghum leaves was consistent with the conclusion in maize (Zea mays) and P. dilatatum leaves (Soares-Cordeiro et al. 2009). Thus, the importance of specific $P_{\mathrm{N}}$ changed with the level of PPFD and illuminating orientations.

The high capacity of $\mathrm{CO}_{2}$ diffusion under high PPFD could improve light-use efficiency and enhance maximum photosynthetic rates. Our results showed that the specific $g_{\mathrm{s}}$ was substantially higher at the abaxial surfaces than that at adaxial ones under high PPFD, and both $g_{\mathrm{s}}$ in incident and self-transmitted light showed the same results (Fig. 5C,D). The superiority of abaxial surface in $\mathrm{CO}_{2}$ diffusion could be proven from morphological structures of leaves, such as SD, ASC, and CABM (Fig. 4). The depression of photosynthesis in high PPFD was mostly due to the stomatal limitation, the higher SD and stomatal size could partly mitigated stomatal limitation (Wang et al. 2008, Wu et al. 2014). The abaxial SD was significantly higher than that of the adaxial one with the same stomatal size in sorghum leaves (Table 1). The higher ASC and SD (Fig. $4 B$ ) could increase the pressure differentials between the leaf and atmosphere, as well as the contact areas between $\mathrm{CO}_{2}$ and mesophyll cells (Wu et al. 2014). Thus, the higher abaxial SD might contribute to the higher $P_{\mathrm{Nmax}}$ 


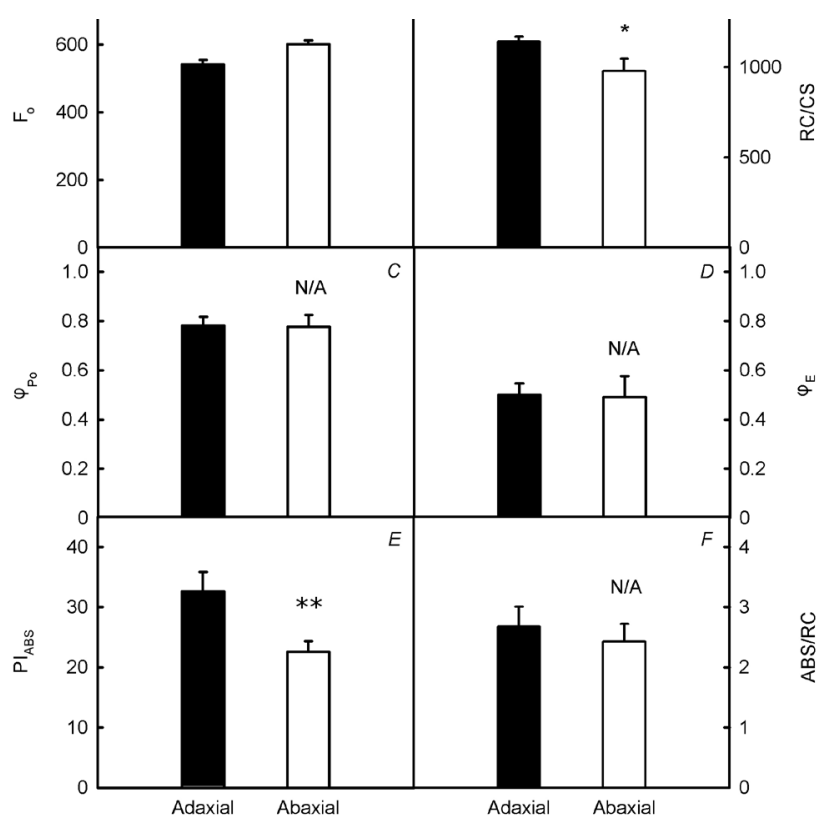

Fig. 6. Variations of minimal fluorescence yield of the darkadapted state $\left(\mathrm{F}_{0}\right)(A)$, concentration of reaction centers per excited cross section (RC/CS) $(B)$, maximum quantum yield of primary photochemistry $\left(\varphi_{\mathrm{P}_{\mathrm{O}}}\right)(C)$, quantum yield of electron transport $\left(\varphi_{\mathrm{E}}\right)(D)$, performance index $\left(\mathrm{PI}_{\mathrm{ABS}}\right)(E)$, and specific energy fluxes per reaction center for absorption $(\mathrm{ABS} / \mathrm{RC})(F)$ in chlorophyll $a$ fluorescence transient test between adaxial (black) and abaxial (white) surface in sorghum. Bars superscripted by different symbols are significantly different, based on one-way ANOVA (* $P=0.05, * * P=0.01)$, ns, not significant between adaxial and abaxial values. Means $\pm \mathrm{SE}, n=24$.

and LSP which were calculated in higher PPFD when the stomatal limitation occurred. The $\mathrm{CO}_{2}$ fixation in $\mathrm{C}_{4}$ plant cells occurs in two steps, requiring the collaboration of mesophyll cells and vascular bundle sheath cells; the rates of gas diffusion between mesophyll cells and vascular bundle sheath cells have great effects on photosynthetic rates (Sowiński et al. 2008). For these reasons, the higher $\mathrm{CABM}$ can increase interface of gas diffusion, which may be crucial in photosynthesis, especially for higher $\mathrm{CO}_{2}$ assimilation rates. The higher CABM at the abaxial surface than that of adaxial surface demonstrated that the potential of $\mathrm{CO}_{2}$ diffusion was higher at the abaxial surface in sorghum leaves. The previous reports also showed that the photosynthetic capacity of $\mathrm{C}_{4}$ isobilateral leaves exposed to direct light tended to be higher for abaxial illumination than that of adaxial illumination, owing to optimal tissue morphology and SD (Long et al. 1989, Driscoll et al. 2006, Soares et al. 2008, Soares-Cordeiro et al. 2011). Therefore, higher specific $P_{\mathrm{N}}$ of the abaxial surface in sorghum leaves was due to the higher $\mathrm{CO}_{2}$ diffusion capacity under high PPFD conditions.

The light absorbance is necessary for photosynthesis (Eberhard et al. 2008, Croce and van Amerongen 2014). The leaf optical properties varied with surface properties, inner structures, pigment component and content, and relative water content in leaves (Gorton et al. 2010).
However, our data demonstrated that absorptance rates of sorghum leaves were almost the same for both the adaxial and abaxial illumination over most of wavelength of 400-800 nm (Fig. 3A). The leaf spectrum properties of Helianthus (Wang et al. 2008, Gorton et al. 2010), Nicotiana tabacum (Falcioni et al. 2017), and Asarum canadense (Brodersen and Vogelmann 2010) had been investigated; it turned out that the leaf absorptance rates were different between adaxial and abaxial illumination. Unlike these bifacial species, the light absorbance capacity was nearly the same whether the light illuminated adaxial or abaxial surface of sorghum leaves. This result was consistent with other studies on isobilateral leaves (DeLucia et al. 1991, Soares et al. 2008, Brodersen and Vogelmann 2010, Gorton et al. 2010). The Chl $a$ fluorescence transient reflects the primary photochemical reaction of PSII and the redox state of photosynthetic apparatus (Strasser et al. 2004). The higher $F_{0}$ of abaxial surface indicated that the activity of reaction center of PSII was a little lower than the adaxial one (Fig. 6A). The slight difference of photochemical activity between the two surfaces could not be reflected from the $\varphi_{P_{0}}\left(1-F_{0} / F_{m}\right)$ in our Chl $a$ fluorescence transient test. The $\mathrm{PI}_{\mathrm{ABS}}$ was much more sensitive as a multi-parametric expression of these independent steps contributing to pho-tosynthesis (Van Heerden et al. 2004). The extremely significant difference of the $\mathrm{PI}_{\mathrm{ABS}}$ values between two sur-faces showed that the photosynthetic apparatus of the adaxial surface was more efficient than that of abaxial one. This explained the higher specific AQE and lower specific LCP of adaxial surface both in incident light and selftransmitted light (Table 2).

The activity of photosynthetic apparatus is determined by light absorbance efficiency, reaction center density, and allocation proportion of quantum yield in photosynthetic components (Strasser et al. 2004, Van Heerden et al. 2004). Our results from fluorescence transient test showed that the specific $\mathrm{ABS} / \mathrm{RC}$ and $\varphi_{\mathrm{E}}$ were nearly the same for both two surfaces (Fig. $6 D, F$ ), indicating that the energetic absorbance and conversion capacity of RC showed no difference between two surfaces. Therefore, the higher apparent adaxial photochemical activity was caused by the higher fraction of active PSII reaction centers per excited cross-section ( $\mathrm{RC} / \mathrm{CS}$ ). The higher $\mathrm{RC} / \mathrm{CS}$ was caused by higher MD in adaxial side (Table 1), which increased the number of reaction center of per area. Thus, the morphology of sorghum leaves caused the higher light capture efficiency and primary photochemical activity at the adaxial surfaces but higher $\mathrm{CO}_{2}$ diffusion capacity at abaxial surfaces, which might be evolutionary adaption in sorghum leaves.

Light-use regulation of photosynthesis in field-grown sorghum: Our study showed that PPFD from different orientations of east, south, west, and north above the canopy was greatly higher than the diffuse light during most hours of a clear sky condition, and the calculated selftransmitted light was also significantly higher than the diffuse light (Fig. 2). Under the self-transmitted light, the specific $P_{\mathrm{N}}$ of abaxial surface could reach to $30.32 \mu \mathrm{mol}$ 
$\mathrm{m}^{-2} \mathrm{~s}^{-1}$, while specific $P_{\mathrm{N} \max }$ of adaxial surface could not exceed $11.23 \mu \mathrm{mol}\left(\mathrm{CO}_{2}\right) \mathrm{m}^{-2} \mathrm{~s}^{-1}$ (Table 2), demonstrating that abaxial surface had higher $\mathrm{CO}_{2}$ assimilation rate than that of adaxial one in self-transmitted light. Wang et al. (2008) investigated the stomatal response of two surfaces in intact leaves of Helianthus annuus L., and proved that the sensitivity to light response was higher in abaxial stomata in self-transmitted light. In addition, Falcioni et al. (2017) showed that self-transmitted light might contain more green light, which was proved more efficient in driving light reaction. Our data showed the specific LCP and AQE of abaxial surface were insignificant in self-transmitted light compared to incident light (Table 2). The abaxial surfaces of field-grown sorghum leaves were almost exposed to diffuse lights, and nearly all the light intensity was below $250 \mu \mathrm{mol}$ (photon) $\mathrm{m}^{-2} \mathrm{~s}^{-1}$ (Fig. $2 B$ ), thus the self-transmitted light would make more contributions on the abaxial photosynthesis. In fact, the diffuse light would be even much lower with the increase of planting density, the PPFD around the abaxial surface was much lower than self-transmitted light. The abaxial surface of leaves retained a high photosynthetic capacity, while the adaxial surface showed a low photosynthetic capacity in self-transmitted light (Fig. 5B). Consequently, the adaxial surface mainly uses direct light to drive light reactions, and abaxial surface mainly uses self-transmitted light to drive light reactions in field-grown sorghum leaves.

For a typical bifacial leaf, $\mathrm{CO}_{2}$ enters intercellular space mainly via the abaxial side, whereas carbon dioxide uptake occurs predominately at the adaxial side. When incident light arrives at adaxial surface, the lens-like epidermal cells of adaxial surface collect and focus direct light into the leaf interior, whereas loose and spherical cells of abaxial surface are beneficial to transmit diffuse lights in bifacial leaves (Jacquemoud and Baret 1990, Smith et al. 1997, Gorton et al. 2010). The rates of $\mathrm{CO}_{2}$ assimilation depend on thickness of mesophyll tissue, because the thick mesophyll tissue increases light retention and absorption (Delaney and Dobrenz 1974). The thickness of mesophyll tissue mainly depends on thickness of palisade tissue (Vogelmann and Martin 1993, Terashima et al. 2001, Coble and Cavaleri 2017). For an isobilateral leaf, both sides are palisade tissues or isodiametric cells, the incident light can be absorbed by two layers of mesophyll cells. The longer transmission paths and recurrent intercepts in sorghum leaves enhanced the light-use efficiency and photosynthetic capacity (Vogelmann and Martin 1993). In addition, sorghum is native to xerothermic area, where the photoinhibition of leaves happens frequently under clear sky conditions. When the incident light intensity is so high to cause photoinhibition, the abaxial side might partly alleviate inhibition under the shading of adaxial mesophyll tissue, which might be crucial to yield improvement (Kromdijk et al. 2016, Slattery et al. 2018). Therefore, the whole leaf can hold high rates of $\mathrm{CO}_{2}$ assimilation under excessive light. In consequence, the use of self-transmitted light for abaxial side is beneficial to enhance the leaf integrated photosynthetic rates.

Conclusion: Based on our study, we concluded that the adaxial surface had higher primary photochemical activity owing to higher $\mathrm{MD}$, and abaxial surface had higher $\mathrm{CO}_{2}-$ diffusion capacity owing to higher $\mathrm{SD}, \mathrm{ASC}$, and CABM in field-grown sorghum leaves. The abaxial surface of fieldgrown sorghum leaves could mainly use self-transmitted light to drive photoreactions, while adaxial surface mainly uses incident light under clear sky conditions, which could adjust to diverse light condition and retain high leaf integrate photosynthetic rates.

\section{References}

Bird R.E., Riordan C.: Simple solar spectral model for direct and diffuse irradiance on horizontal and tilted planes at the Earth's surface for cloudless atmospheres. - J. Clim. Appl. Meteorol. 25: 87-97, 1986.

Brodersen C.R.,Vogelmann T.C.: Do changes in light direction affect absorption profiles in leaves? - Funct. Plant Biol. 37: 403-412, 2010.

Centritto M., Loreto F., Chartzoulakis K.: The use of low $\left[\mathrm{CO}_{2}\right]$ to estimate diffusional and non-diffusional limitations of photosynthetic capacity of salt-stressed olive saplings. - Plant Cell Environ. 26: 585-594, 2003.

Coble A.P., Cavaleri M.A.: Vertical leaf mass per area gradient of mature sugar maple reflects both height-driven increases in vascular tissue and light-driven increases in palisade layer thickness. - Tree Physiol. 37: 1337-1351, 2017.

Coupe S.A., Palmer B.G., Lake J.A. et al.: Systemic signalling of environmental cues in Arabidopsis leaves. - J. Exp. Bot. 57: 329-341, 2006.

Croce R.,van Amerongen H.: Natural strategies for photosynthetic light harvesting. - Nat. Chem. Biol. 10: 492-501, 2014.

Delaney R.H., Dobrenz A.K.: Morphological and anatomical features of alfalfa leaves as related to $\mathrm{CO}_{2}$ exchange. - Crop Sci. 14: 444-447, 1974.

DeLucia E.H., Shenoi H.D., Naidu S.L., Day T.A.: Photosynthetic symmetry of sun and shade leaves of different orientations. Oecologia 87: 51-57, 1991.

Driscoll S.P., Prins A., Olmos E. et al.: Specification of adaxial and abaxial stomata, epidermal structure and photosynthesis to $\mathrm{CO}_{2}$ enrichment in maize leaves. - J. Exp. Bot. 57: 381-390, 2006.

Earles J.M., Théroux-Rancourt G., Gilbert M.E. et al.: Excess diffuse light absorption in upper mesophyll limits $\mathrm{CO}_{2}$ drawdown and depresses photosynthesis. - Plant Physiol. 174: 1082-1096, 2017.

Eberhard S., Finazzi G.,Wollman F.-A.: The dynamics of photosynthesis. - Annu. Rev. Genet. 42: 463-515, 2008.

Ehleringer J.R., Björkman O.: Pubescence and leaf spectral characteristics in a desert shrub, Encelia farinosa.-Oecologia 36: 151-162, 1978.

Falcioni R., Moriwaki T., Bonato C.M. et al.: Distinct growth light and gibberellin regimes alter leaf anatomy and reveal their influence on leaf optical properties. - Environ. Exp. Bot. 140: 86-95, 2017.

Flexas J., Diaz-Espejo A., Galmes J. et al.: Rapid variations of mesophyll conductance in response to changes in $\mathrm{CO}_{2}$ concentration around leaves. - Plant Cell Environ. 30: 1284-1298, 2007.

Gamon J.A., Surfus J.S.: Assessing leaf pigment content and activity with a reflectometer. - New Phytol. 143: 105-117, 1999.

Gorton H.L., Brodersen C.R., Williams W.E., Vogelmann T.C.: Measurement of the optical properties of leaves under diffuse light. - Photochem. Photobiol. 86: 1076-1083, 2010. 
Jacquemoud S., Baret F.: PROSPECT: A model of leaf optical properties spectra. - Remote Sens. Environ. 34: 75-91, 1990.

Jiang C.D., Wang X., Gao H.Y. et al.: Systemic regulation of leaf anatomical structure, photosynthetic performance, and highlight tolerance in Sorghum. - Plant Physiol. 155: 1416-1424, 2011.

Jordan G.J., Carpenter R.J., Koutoulis A. et al.: Environmental adaptation in stomatal size independent of the effects of genome size. - New Phytol. 205: 608-617, 2015.

Kromdijk J., Głowacka K., Leonelli L. et al.: Improving photosynthesis and crop productivity by accelerating recovery from photoprotection. - Science 354: 857-861, 2016.

Long S.P., Farage P.K., Bolhár-Nordenkampf H.R., Ruhrhofer U.: Separating the contribution of the upper and lower mesophyll to photosynthesis in Zea mays L. leaves. - Planta 177: 207-216, 1989.

Morison J.I.L.,Lawson T.: Does lateral gas diffusion in leaves matter? - Plant Cell Environ. 30: 1072-1085, 2007.

Moss D.N.: Optimum lighting of leaves. - Crop Sci. 4: 131-136, 1964.

Muir C.D., Hangarter R.P., Moyle L.C., Davis P.A.: Morphological and anatomical determinants of mesophyll conductance in wild relatives of tomato (Solanum sect. Lycopersicon, sect. Lycopersicoides; Solanaceae). - Plant Cell Environ. 37: 1415-1426, 2014.

Richardson F., Brodribb T.J., Jordan G.J.: Amphistomatic leaf surfaces independently regulate gas exchange in response to variations in evaporative demand. - Tree Physiol. 37: 869-878, 2017.

Slattery R.A., Walker B.J., Weber A.P.M., Ort D.R.: The impacts of fluctuating light on crop performance. - Plant Physiol. 176: 990-1003, 2018.

Smith W.K.: $\mathrm{C}_{4}$ leaf curling coupling incident light, stomatal and photosynthetic asymmetries. - New Phytol. 177: 5-8, 2008.

Smith W.K., Vogelmann T.C., DeLucia E.H. et al.: Leaf form and photosynthesis. - Bioscience 47: 785-793, 1997.

Soares A.S., Driscoll S.P., Olmos E. et al.: Adaxial/abaxial specification in the regulation of photosynthesis and stomatal opening with respect to light orientation and growth with $\mathrm{CO}_{2}$ enrichment in the $\mathrm{C}_{4}$ species Paspalum dilatatum. - New Phytol. 177: 186-198, 2008.

Soares-Cordeiro A.S., Driscoll S.P., Arrabaça M.C., Foyer C.H.: Dorsoventral variations in dark chilling effects on photosynthesis and stomatal function in Paspalum dilatatum leaves. J. Exp. Bot. 62: 687-699, 2011

Soares-Cordeiro A.S., Driscoll S.P., Pellny T.K. et al.: Variations in the dorsoventral organization of leaf structure and Kranz anatomy coordinate the control of photosynthesis and associated signalling at the whole leaf level in monocotyledonous species. - Plant Cell Environ. 32: 1833-1844, 2009.

Soares A.S., Driscoll S.P., Olmos E. et al.: Adaxial/abaxial specification in the regulation of photosynthesis and stomatal opening with respect to light orientation and growth with $\mathrm{CO} 2$ enrichment in the $\mathrm{C} 4$ species Paspalum dilatatum. - New
Phytol. 177: 186-198, 2008.

Sowiński P., Szczepanik J., Minchin P.E.H.: On the mechanism of $\mathrm{C}_{4}$ photosynthesis intermediate exchange between Kranz mesophyll and bundle sheath cells in grasses. - J. Exp. Bot. 59: 1137-1147, 2008.

Strasser R.J., Tsimilli-Michael M., Srivastava A.: Analysis of the chlorophyll $a$ fluorescence transient. - In: Papageorgiou G.C., Govindjee (ed.): Chlorophyll $a$ Fluorescence: A Signature of Photosynthesis. Pp. 321-362. Springer Netherlands, Dordrecht 2004.

Sun J., Nishio J.N., Vogelmann T.C.: Green light drives $\mathrm{CO}_{2}$ fixation deep within leaves. - Plant Cell Physiol. 39: 1020-1026, 1998.

Terashima I., Fujita T., Inoue T. et al.: Green light drives leaf photosynthesis more efficiently than red light in strong white light: revisiting the enigmatic question of why leaves are green. - Plant Cell Physiol. 50: 684-697, 2009.

Terashima I., Inoue Y.: Comparative photosynthetic properties of palisade tissue chloroplasts and spongy tissue chloroplasts of Camellia japonica L.: functional adjustment of the photosynthetic apparatus to light environment within a leaf. Plant Cell Physiol. 25: 555-563, 1984.

Terashima I., Miyazawa S.-I., Hanba Y.T.: Why are sun leaves thicker than shade leaves? - Consideration based on analyses of $\mathrm{CO}_{2}$ diffusion in the leaf. - J. Plant Res. 114: 93-105, 2001.

Thain J.F.: Curvature correction factors in the measurement of cell-surface areas in plant tissues. - J. Exp. Bot. 34: 87-94, 1983.

Tsimilli-Michael M., Eggenberg P., Biro B. et al.: Synergistic and antagonistic effects of arbuscular mycorrhizal fungi and Azospirillum and Rhizobium nitrogen-fixers on the photosynthetic activity of alfalfa, probed by the polyphasic chlorophyll $a$ fluorescence transient O-J-I-P. - Appl. Soil Ecol. 15: 169-182, 2000.

Van Heerden P.D., Strasser R.J., Krüger G.H.: Reduction of dark chilling stress in $\mathrm{N}_{2}$-fixing soybean by nitrate as indicated by chlorophyll $a$ fluorescence kinetics. - Physiol. Plantarum 121: 239-249, 2004.

Vogelmann T.C., Bornman J.F., Yates D.J.: Focusing of light by leaf epidermal cells. - Physiol. Plantarum 98: 43-56, 1996.

Vogelmann T.C., Martin G.: The functional significance of palisade tissue: penetration of directional versus diffuse light. - Plant Cell Environ. 16: 65-72, 1993.

Wang Y., Noguchi K.,Terashima I.: Distinct light responses of the adaxial and abaxial stomata in intact leaves of Helianthus annuus L. - Plant Cell Environ. 31: 1307-1316, 2008.

Wu B.J., Chow W.S., Liu Y.J. et al.: Effects of stomatal development on stomatal conductance and on stomatal limitation of photosynthesis in Syringa oblata and Euonymus japonicus Thunb. - Plant Sci. 229: 23-31, 2014.

Xiong D., Douthe C., Flexas J.: Differential coordination of stomatal conductance, mesophyll conductance, and leaf hydraulic conductance in response to changing light across species. Plant Cell Environ. 41: 436-450, 2018.

(C) The authors. This is an open access article distributed under the terms of the Creative Commons BY-NC-ND Licence. 